\title{
Кинетика сорбции ионов меди, никеля и кобальта при совместном присутствии из водных растворов цеолитами
}

\author{
Белова Т.П. \\ Федеральное государственное бюджетное учреждение науки Научно-исследовательский геотехно- \\ логический центр Дальневосточного отделения Российской академии наук \\ (НИГТЦ ДВО РАН), Петропавловск-Камчатский
}

Поступила в редакцию 15.03.2017 г.

DOI: https://doi.org/10.17308/sorpchrom.2018.18/535

Экспериментально исследовано взаимное влияние на кинетику сорбции ионов меди (II), никеля (II) и кобальта (II) при совместном присутствии цеолитом Ягоднинского месторождения Камчатского края. Показано, что лимитирующей стадией сорбции является внутридиффузионный механизм. Для каждого иона рассчитаны величина сорбционной емкости, коэффициент внутренней диффузии, константа скорости реакции обмена по моделям псевдо-первого и псевдо-второго порядков.

Ключевые слова: сорбция, сорбционная емкость, коэффициент внутренней диффузии, цеолит, медь, никель, кобальт.

\section{Sorption kinetics of copper, nickel and cobalt ions under their compresence from aqueous solutions by zeolites}

\author{
Belova T.P. \\ Federal State Budgetary Institution of Research Geotechnological Center, Far Eastern Branch, Russian \\ Academy of Sciences (RGC FEB RAS), Petropavlovsk-Kamchatsky
}

The mutual influence on the kinetics of the sorption of copper (II), nickel (II) and cobalt (II) ions (under their compresence) by natural zeolite of Yagodninsky deposit (Kamchatka) was experimentally investigated. Mineral composition of the zeolite tuffs of the Yagodninsky deposit of the Kamchatka Krai are represented by clinoptilolite (up to 70\%) and mordenite (up to 10\%). Cristobalite, quartz, mica and clay minerals account for up to $20 \%$. Clinoptilolite of the Yagodninsky deposit is represented by a polycationic Na-KCa-form. The dominant replaceable cations in clinoptilolite are alkali metals: $\mathrm{Na}^{+}$and $\mathrm{K}^{+}$. Mordenite is characterized by the predominance of $\mathrm{Ca}^{2+}$ ions. The natural form of zeolite is not only homogeneous single crystals, but also aggregates in the form of mineral grains intergrowths.

The value of sorption capacity, the coefficient of internal diffusion, the rate constant of exchange reaction according to the models of pseudo-first and pseudo-second order were calculated for each ion. The calculated diffusion coefficients, reaction rate constants $k_{l}$ (pseudo-first-order model, $\mathrm{c}^{-1}$ ) and $k_{2}$ (pseudosecond-order model, $\left.\mathrm{g} \cdot \mathrm{mmol}-\mathrm{eq}^{-1} \cdot \mathrm{s}^{-1}\right)$, high correlation coefficients confirm that the diffusion of exchangeable ions in the crystal lattice of minerals is the limiting factor.

The sorption capacity of zeolite from individual solutions decreases in the series $\mathrm{Cu}>\mathrm{Ni}>\mathrm{Co}$ and it is $31.7,27.0,23.0 \mathrm{mmol}-\mathrm{eq} / \mathrm{kg}$, respectively. The presence of copper (II) ions in the solution affects much on the sorption of nickel and cobalt from aqueous solutions of complex composition. It is, probably, connected 
with the crystal-chemical radius of copper (II) ion. Compared to nickel (II) ions and cobalt (II) ions it is the largest. balt.

Keywords: sorption, sorption capacity, coefficient of internal diffusion, zeolite, copper, nickel, co-

\section{Введение}

Камчатский край располагает значительными минерально-сырьевыми ресурсами для развития горнодобывающей промышленности. В настоящее время разрабатывается сульфидное кобальт-медно-никелевое месторождение Шануч. Однако, добытая руда перерабатывается за пределами региона. Развитие горноперерабатывающей отрасли в регионе является перспективным направлением. В НИГТЦ ДВО РАН ведутся исследования чанового бактериально-химического выщелачивания (БХВ) руды месторождения Шануч. Наряду с высококонцентрированными продуктивными растворами в ходе БХВ образуются низкоконцентрированные промывные воды и сточные воды. Неизбежно часть ценных металлов безвозвратно теряется со сточными водами. Для извлечения цветных металлов из промывных и сточных вод перспективным сорбентом является цеолитовое сырье Ягоднинского месторождения Камчатского края [1-5]. Использование цеолитов месторождений Камчатского края для сохранения экологической ситуации в районах горноперерабатывающих предприятий и получение сведений о кинетике сорбции цветных металлов представляется актуальной задачей.

Адсорбция из растворов на твердых адсорбентах это сложный процесс самопроизвольного перераспределения растворенного вещества между фазами. Для гетерогенных реакций принято выделять пять стадий: диффузия сорбируемых ионов из раствора к поверхности твердой фазы (внешняя диффузия); диффузия сорбируемых ионов внутрь зерна твердой фазы (внутренняя диффузия); химическая реакция обмена ионов; диффузия противоионов из внутренней зоны твердой фазы к поверхности раздела фаз; диффузия противоионов в фазу раствора. Таким образом, в начальный момент времени массообмен проходит на поверхности твердой фазы, процесс лимитируется внешней диффузией. По мере заполнения поверхности включается механизм внутридиффузионной кинетики и лимитирующим фактором становится коэффициент внутренней диффузии. При переходе от внешнедиффузионной кинетической области к внутридиффузионной существует состояние системы, которое характеризуется смешанно-диффузионной кинетикой [6-7]. Для каждой области массообмена в литературе описаны математические модели.

Экспериментальное исследование кинетики сорбции заключается в выявлении лимитирующей стадии процесса. Известно, что для определения скорости сорбции необходимо учитывать большое количество параметров, к числу которых относятся поверхностные и физико-химические свойства адсорбента, физико-химические свойства сорбируемых ионов, взаимное влияние компонентов жидкой фазы, а так же внешние условия. Частным случаем адсорбции из растворов является ионный обмен, который протекает в строгом соответствии со стехиометрическими законами и законами электронейтральности фаз. Для исследования закономерностей сорбции цветных металлов цеолитами необходимо получение сведений не только о физикохимических свойствах твердой фазы, но и составе водной фазы.

Целью настоящей работы является установление взаимного влияния компонентов раствора на процессы сорбции ионов меди (II), никеля (II) и кобальта (II) цеолитами Ягоднинского месторождения Камчатского края. 


\section{Эксперимент}

Эксперименты по установлению взаимного влияния ионов меди, никеля и кобальта на кинетику сорбции цеолитом Ягоднинского месторождения Камчатского края вели методом ограниченного объема при комнатной температуре $\left(20 \pm 2^{\circ} \mathrm{C}\right)$. Подготовку цеолита проводили следующим образом: пробу измельчали в щековой дробилке, на ситах выделяли фракцию с заданными размерами частиц, отмывали дистиллированной водой декантацией, сушили на воздухе при комнатной температуре. Навески воздушно-сухого цеолита помещали в конические колбы, добавляли модельные индивидуальные, бинарные и тройные растворы с различного состава в массовом соотношении $\mathrm{T}: Ж=1: 20$ и устанавливали в аппарат для встряхивания. Пробы объемом $0.5 \mathrm{~cm}^{3}$ отбирали через определенные промежутки времени: 1, 2, 4, 6 и 24 час. Перед анализом пробы разбавляли $0.7 \mathrm{M}$ соляной кислотой. Исходные бинарные растворы содержали по 50 мг/дм ${ }^{3}$ каждого иона, в тройном растворе содержание каждого иона составляло $33.3 \mathrm{мг} /$ дм $^{3}$. Таким образом, общее солесодержание сохранялось на уровне 100 мг/дм³. Для приготовления модельных растворов использовали $\mathrm{CuSO}_{4} \cdot 5 \mathrm{H}_{2} \mathrm{O}$ (ч.д.а. ГОСТ 4165-78); $\mathrm{NiSO}_{4} \cdot 7 \mathrm{H}_{2} \mathrm{O}$ (х.ч. ГОСТ 4528-78); $\mathrm{Co}\left(\mathrm{NO}_{3}\right)_{2} \cdot 6 \mathrm{H}_{2} \mathrm{O}$ (ч.д.а. ГОСТ 4528-78).

Содержание катионов меди, никеля и кобальта в растворах определяли методом атомно-абсорбционной спектроскопии, используя AAS-6300 фирмы «Shimadzu» (Япония), с применением метода атомизации в ацетилено-воздушном пламени. Погрешность определения для меди составляла $\pm 10 \%$, для кобальта $\pm 13 \%$, для никеля $\pm 14 \%$.

\section{Обсуждение результатов}

В обширную группу неорганических ионообменных материалов входят широко распространенные в природе минералы. Использование минералов переменного состава в качестве высокоселективных ионитов обусловлено их устойчивостью к термическим воздействиям, агрессивным средам и радиоактивному излучению [7]. По минеральному составу цеолитовые туфы Ягоднинского месторождения Камчатского края представлены клиноптилолитом (до 70\%) и морденитом (до 10\%). На долю кристобалита, кварца, слюды и глинистых минералов приходится до 20\% [1-2]. Химический состав цеолитового туфа, массовая доля, \%: $\mathrm{SiO}_{2}-66-72, \mathrm{Al}_{2} \mathrm{O}_{3}-11-$ $14, \mathrm{Fe}_{2} \mathrm{O}_{3}-0.6-1.7, \mathrm{CaO}-0.5-2.0, \mathrm{MgO}-0.1-0.5, \mathrm{MnO}-0,06, \mathrm{~K}_{2} \mathrm{O}-2.8-4.8, \mathrm{Na}_{2} \mathrm{O}-$ $1.34-3.55, \mathrm{TiO}_{2}-0.23-0.45, \mathrm{P}_{2} \mathrm{O}_{5}-0.01, \mathrm{H}_{2} \mathrm{O}-3.7-13.5$. Наиболее вероятная кристаллохимическая формула клиноптилолита $(\mathrm{Na}, \mathrm{K})_{4} \mathrm{CaAl}_{6} \mathrm{Si}_{30} \mathrm{O}_{72} \times 24 \mathrm{H}_{2} \mathrm{O}$. Клинопти-

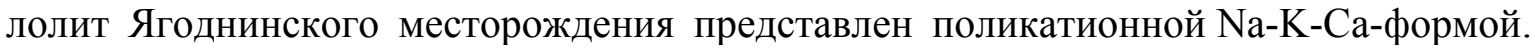
Доминирующими заменяемыми катионами в клиноптилолите являются щелочные металлы $-\mathrm{Na}^{+}$и $\mathrm{K}^{+}$. Для морденита характерно преобладание содержания $\mathrm{CaO}$ по отношению к сумме $\mathrm{Na}_{2} \mathrm{O}+\mathrm{K}_{2} \mathrm{O}$ [4].

Иониты на основе минералов имеют структуру в виде каркаса, заряженного положительно или отрицательно и противоиона, уравновешивающего заряд каркаса. Наиболее часто используемые модели для описания кинетики сорбции - это модели псевдо-первого порядка, псевдо-второго порядка, модифицированного второго порядка, модель Еловича [5, 8-12]. В рамках данной статьи принято решение ограничиться рассмотрением первых двух моделей.

Модель псевдо-первого порядка выражается интегральным уравнением:

$$
a_{t}=a_{e q}\left(1-e^{-k_{1} t}\right) \text {. }
$$

Модель псевдо-второго порядка: 


$$
a_{t}=\frac{t}{\frac{1}{k_{2} a_{e q}^{2}}+\frac{t}{a_{e q}}},
$$

где $a_{t}$ и $a_{e q}$ - количество сорбированного металла в момент времени $t$ и в состоянии равновесия, соответственно, ммоль-экв/г; $k_{l}$ - константа скорости сорбции модели псевдо-первого порядка, $\mathrm{c}^{-1} ; k_{2}$ - константа скорости сорбции псевдо-второго порядка, г'ммоль-экв ${ }^{-1} \cdot \mathrm{c}^{-1}$.

Уравнение (1),описывающее модель псевдо-первого порядка, в координатах $\ln (1-F)$ от $t$ имеет прямолинейный характер. Здесь $F$ - степень достижения равновесия, рассчитываемая по формуле: $F=a_{t} / a_{e q}$. Модель псевдо-второго порядка (уравнение 2) линеализуется в координатах $t / a_{t}$ от $t$.

По экспериментальным данным строили графические зависимости степени завершенности процесса F от корня квадратного из времени. На основании экспериментальных данных были рассчитаны коэффициенты диффузии $\mathrm{D}_{e f}$ ионов меди, никеля и кобальта в цеолите. Расчет коэффициента диффузии ионов проводили графоаналитически исходя из уравнений для сферических частиц $[1,2,10]$ :

$$
F=\frac{6}{r} \sqrt{\frac{D_{e f} t}{\pi}}, \quad D_{e f}=\frac{\pi \cdot r^{2}}{36} \cdot \operatorname{tg}^{2} \alpha,
$$

где $\alpha$ - угол наклона прямой в координатах $\mathrm{F}-\sqrt{t}$

В условиях внутридиффузионной кинетики величина коэффициета диффузии $\mathrm{D}$ имеет порядок $10^{-8}-10^{-9} \mathrm{~cm}^{2} / \mathrm{c}$ и меньше; внешнедиффузионной кинетики $-10^{-5}$ $10^{-6} \mathrm{~cm}^{2} / \mathrm{c}$, что соответствует значениям наиболее характерным для свободных ионов в растворах; смешанно-диффузионной кинетики $-10^{-7}-10^{-8} \mathrm{~cm}^{2} / \mathrm{c}$.

Полученные кинетические данные были обработаны в рамках моделей кинетики псевдо-первого и псевдо-второго порядков. Для определения времени достижения сорбционного равновесия были построены кинетические кривые в координатах $F-t$. В интервале времени от начала сорбции $\mathrm{t}_{0}$ до времени установления равновесия $\mathrm{t}_{\mathrm{eq}}$ между раствором и сорбентом можно выделить три интервала [7]. В первом интервале времени - от $\mathrm{t}_{0}$ до $\mathrm{t}_{1}$ при низких степенях достижения сорбционного равновесия $\mathrm{F}$ обмен между ионами раствора и твердой фазы протекает на поверхности сорбента, т.е. по внешнедиффузионному механизму. Обычно $t_{1}$ очень мало и не превышает 30 мин. В условиях данного эксперимента первое измерение было проведено через 1 час, поэтому определение коэффициента внешней диффузии затруднено. В интервале времени от $t_{1}$ до $t_{2}$ сорбция проходит по смешанному механизму, скорость сорбции определяется отношением скоростей обмена на поверхности и внутри зерна цеолита. В интервале времени от $t_{2}$ до $t_{\text {eq }}$ сорбция проходит преимущественно по внутридиффузионному механизму.

Графоаналитическим методом установлено, что время полусорбции $\left(\mathrm{t}_{1 / 2}\right)$ для ионов цветных металлов из индивидуальных растворов составляет: для ионов меди (II) $-6.2 \cdot 10^{3} \mathrm{c}$; для ионов никеля (II) $-5.8 \cdot 10^{3}$ с; для ионов кобальта (II) $-6.4 \cdot 10^{3} \mathrm{c}$ (табл. 1). Время полусорбции $\left(\mathrm{t}_{1 / 2}\right)$ для ионов цветных металлов в системе - цеолитбинарный раствор зависит от состава раствора. Так, время полусорбции ионов меди (II) в присутствии ионов никеля (II) составляет $7.2 \cdot 10^{3}$ с, а время полусорбции никеля в присутствии меди $-7.5 \cdot 10^{3}$ с. При сорбции из бинарного раствора, содержащего ионы меди (II) и ионы кобальта (II) время полусорбции составило $11.0 \cdot 10^{3}$ с для меди и $8.7 \cdot 10^{3}$ с для кобальта. При сорбции из раствора, содержащего одновременно ионы никеля (II) и ионы кобальта (II) время полусорбции составило: $6.2 \cdot 10^{3}$ и $6.6 \cdot 10^{3}$ с, соответственно. При сорбции в системе - цеолит-тройной раствор также наблюдается зависимость сорбционных характеристик от состава раствора. При сорбции цветных 
металлов из раствора, содержащего одновременно все три иона время полусорбции составило $6.8 \cdot 10^{3}$ с для меди, 8.7·10 ${ }^{3}$ с для никеля и $6.15 \cdot 10^{3}$ с для кобальта.

Таблица 1. Влияние состава раствора на сорбционную емкость цеолитов Ягоднинского месторождения Камчатского края и время полусорбции по отношению к ионам меди (II), никеля (II) и кобальта (II)

\begin{tabular}{|c|c|c|c|c|c|c|}
\hline \multirow[b]{2}{*}{ Состав раствора } & \multicolumn{2}{|c|}{$\mathrm{Cu}^{2+}$} & \multicolumn{2}{|c|}{$\mathrm{Ni}^{2+}$} & \multicolumn{2}{|c|}{$\mathrm{Co}^{2+}$} \\
\hline & $\begin{array}{c}a_{e q}, \\
\text { ммоль- } \\
\text { ЭКВ/кГ }\end{array}$ & $\begin{array}{c}\mathrm{t}_{1 / 2} \cdot 10^{-3} \\
\mathrm{c}\end{array}$ & $\begin{array}{c}a_{e q}, \\
\text { ммоль- } \\
\text { ЭКВ/кГ }\end{array}$ & $\mathrm{t}_{1 / 2} \cdot 10^{-3}, \mathrm{c}$ & $\begin{array}{c}a_{e q}, \\
\text { ммоль- } \\
\text { ЭКВ/кГ }\end{array}$ & $\mathrm{t}_{1 / 2} \cdot 10^{-3}, \mathrm{c}$ \\
\hline $\mathrm{Cu}^{2+}+\mathrm{Ni}^{2+}$ & 20.1 & 7.2 & 14.0 & 7.5 & - & - \\
\hline $\mathrm{Cu}^{2+}+\mathrm{Co}^{2+}$ & 21.8 & 11.0 & - & - & 19.0 & 8.7 \\
\hline $\mathrm{Ni}^{2+}+\mathrm{Co}^{2+}$ & - & - & 24.2 & 6.2 & 21.5 & 6.6 \\
\hline $\begin{array}{c}\mathrm{Cu}^{2+}+\mathrm{Ni}^{2+}+ \\
\mathrm{Co}^{2+}\end{array}$ & 10.2 & 6.8 & 5.0 & 8.7 & 11.0 & 6.2 \\
\hline \multirow{3}{*}{$\begin{array}{c}\text { Индивидуальные } \\
\text { растворы }\end{array}$} & 31.7 & 6.2 & - & - & - & - \\
\hline & - & - & 27.0 & 5.8 & - & - \\
\hline & - & - & - & - & 23.0 & 6.4 \\
\hline
\end{tabular}

Сорбционная емкость цеолита (табл. 1) из индивидуальных растворов уменьшается в ряду $\mathrm{Cu}>\mathrm{Ni}>\mathrm{Co}$, что согласуется с кристаллохимическими радиусами ионов, и составляет соответственно, ммоль-экв/кг: 31.7, 27.0, 23.0. При сорбции из сложных растворов, наибольшая сорбционная емкость цеолита по отношению к ионам меди (II) наблюдается при сорбции из бинарного раствора, содержащего наряду с ионами меди (II) ионы кобальта (II). Наибольшая сорбционная емкость цеолита по отношению к ионам никеля (II) прослеживается также в присутствии кобальта. Максимальная сорбционная емкость цеолита по ионам кобальта (II) проявляется в присутствии никеля. Таким образом, можно сделать вывод о том, что на сорбцию никеля и кобальта из водных растворов наибольшее влияние оказывает присутствие в растворе ионов меди (II).

Изучение кинетики ионообменных реакций на цеолитах показывает, что лимитирующей стадией является диффузия обменных ионов в кристаллической решетке минералов. Отмечается, что при определении полной обменной емкости природных цеолитов возникают трудности, связанные с их структурными особенностями $[6,7]$. За счет этого равновесная величина обменной емкости отличается от теоретической. Поэтому определение обменной емкости представляет собой важную задачу в экспериментальных исследованиях.

Рассчитанные константы скорости сорбции $k_{1}$ (модель псевдо-первого порядка, $\left.\mathrm{c}^{-1}\right)$ и $k_{2}$ (модель псевдо-второго порядка, $\Gamma^{\cdot}$ ммоль-экв $\left.{ }^{-1} \cdot \mathrm{c}^{-1}\right)$ приведены в табл. 2. Высокие значения коэффициентов корреляции $\mathrm{R}^{2}$ подтверждают адекватность применения уравнений 1 и 2 для описания процесса сорбции ионов цветных металлов из растворов различного состава цеолитами. Лишь в единственном случае при сорбции из бинарного раствора, содержащего ионы $\mathrm{Cu}^{2+}$ и $\mathrm{Co}^{2+}$ коэффициент корреляции $\mathrm{R}^{2}=0.605$. Низкое значение коэффициента корреляции свидетельствует о том, что модель псевдо-второго порядка не может быть применена для описания сорбции из бинарного раствора, содержащего ионы $\mathrm{Cu}^{2+}$ и $\mathrm{Co}^{2+}$. Вероятно, обмен ионов происходит преимущественно по реакции псевдо-первого порядка.

Необходимо отметить, что график $\ln (1-F)$ от $t$ имеет прямолинейный характер при низких степенях заполнения, когда внешнедиффузионный механизм преобладает над внутридиффузионным. График в координатах $t / a_{t}$ от $t$ линеен при более высо- 
ких степенях заполнения, когда наблюдается преобладание внутридиффузионного механизма сорбции.

Таблица 2. Параметры кинетических моделей сорбции

\begin{tabular}{|c|c|c|c|c|c|}
\hline \multirow[b]{2}{*}{ Состав раствора } & \multirow[b]{2}{*}{ Ион } & \multicolumn{2}{|c|}{$\begin{array}{c}\text { Модель } \\
\text { псевдо-первого порядка }\end{array}$} & \multicolumn{2}{|c|}{$\begin{array}{c}\text { Модель } \\
\text { псевдо-второго порядка } \\
\end{array}$} \\
\hline & & $k_{1} \cdot 10^{4}, \mathrm{c}^{-1}$ & $\mathrm{R}_{1}^{2}$ & $\begin{array}{c}k_{2} \cdot 10^{8}, \\
\Gamma^{\cdot} \text { ммоль-ЭКв }^{-} \\
{ }^{1} \cdot \mathrm{c}^{-1}\end{array}$ & $\mathrm{R}_{2}^{2}$ \\
\hline \multirow{2}{*}{$\mathrm{Cu}^{2+}+\mathrm{Ni}^{2+}$} & $\mathrm{Cu}^{2+}$ & 1.1 & 0.996 & 1.61 & 0.987 \\
\hline & $\mathrm{Ni}^{2+}$ & 1.0 & 0.989 & 2.95 & 0.999 \\
\hline \multirow{2}{*}{$\mathrm{Cu}^{2+}+\mathrm{Co}^{2+}$} & $\mathrm{Cu}^{2+}$ & 0.81 & 0.984 & $1.33 \cdot 10^{-12}$ & 0.605 \\
\hline & $\mathrm{Co}^{2+}$ & 0.35 & 0.981 & 2.32 & 0.961 \\
\hline \multirow{2}{*}{$\mathrm{Ni}^{2+}+\mathrm{Co}^{2+}$} & $\mathrm{Ni}^{2+}$ & 0.93 & 0.929 & 5.90 & 0.977 \\
\hline & $\mathrm{Co}^{2+}$ & 1.2 & 0.986 & 3.59 & 0.999 \\
\hline \multirow{3}{*}{$\mathrm{Cu}^{2+}+\mathrm{Ni}^{2+}+\mathrm{Co}^{2+}$} & $\mathrm{Cu}^{2+}$ & 0.62 & 0.960 & $1.26 \cdot 10^{-7}$ & 0.999 \\
\hline & $\mathrm{Ni}^{2+}$ & 0.90 & 0.996 & $1.06 \cdot 10^{-7}$ & 0.968 \\
\hline & $\mathrm{Co}^{2+}$ & 0.46 & 0.798 & $2.01 \cdot 10^{-7}$ & 0.956 \\
\hline \multirow{3}{*}{$\begin{array}{c}\text { Индивидуальные } \\
\text { растворы }\end{array}$} & $\mathrm{Cu}^{2+}$ & 1.1 & 0.999 & 2.23 & 0.999 \\
\hline & $\mathrm{Ni}^{2+}$ & 1.0 & 0.994 & 2.44 & 0.976 \\
\hline & $\mathrm{Co}^{2+}$ & 1.0 & 0.995 & 2.88 & 0.995 \\
\hline
\end{tabular}

Графическая зависимость F- $\sqrt{t}$ мультилинейна [8], для расчета коэффициентов внутренней диффузии использовали уравнение 3, принимая во внимание линейность графика при степенях заполнения больше 0.5. Рассчитанные коэффициенты диффузии для радиусов зерен цеолита $0.05,0.025$ и 0.0125 см приведены в таблице 3.

Таблица 3. Зависимость коэффициентов внутренней диффузии $D_{e f}$ от размера частиц и состава раствора

\begin{tabular}{|c|l|c|c|c|}
\hline \multirow{2}{*}{ Состав раствора } & \multirow{2}{*}{ Ион } & \multicolumn{3}{|c|}{$\mathrm{D}_{\text {ef }} 10^{9}, \mathrm{~cm}^{2} / \mathrm{c}$} \\
\cline { 3 - 5 } & & $\mathrm{r}=0.05 \mathrm{~cm}$ & $\mathrm{r}=0.025 \mathrm{~cm}$ & $\mathrm{r}=0.0125 \mathrm{~cm}$ \\
\hline \multirow{2}{*}{$\mathrm{Cu}^{2+}+\mathrm{Ni}^{2+}$} & $\mathrm{Cu}^{2+}$ & 12.1 & 2.99 & 0.75 \\
\cline { 2 - 5 } & $\mathrm{Ni}^{2+}$ & 8.70 & 2.17 & 0.55 \\
\hline \multirow{2}{*}{$\mathrm{Cu}^{2+}+\mathrm{Co}^{2+}$} & $\mathrm{Cu}^{2+}$ & 14.9 & 3.68 & 0.93 \\
\cline { 2 - 5 } & $\mathrm{Co}^{2+}$ & 8.25 & 2.04 & 0.51 \\
\hline \multirow{2}{*}{$\mathrm{Ni}^{2+}+\mathrm{Co}^{2+}$} & $\mathrm{Ni}^{2+}$ & 18.9 & 4.69 & 1.18 \\
\cline { 2 - 5 } & $\mathrm{Co}^{2+}$ & 8.22 & 2.04 & 0.51 \\
\hline \multirow{3}{*}{$\mathrm{Cu}^{2+}+\mathrm{Ni}^{2+}+\mathrm{Co}^{2+}$} & $\mathrm{Cu}^{2+}$ & 4.79 & 1.19 & 0.30 \\
\cline { 2 - 5 } & $\mathrm{Ni}^{2+}$ & 9.10 & 2.25 & 0.57 \\
\cline { 2 - 5 } & $\mathrm{Co}^{2+}$ & 0.50 & 0.12 & - \\
\hline \multirow{2}{*}{ Индивидуальные } \\
растворы & $\mathrm{Cu}^{2+}$ & - & 2.28 & - \\
\cline { 2 - 5 } & $\mathrm{Ni}^{2+}$ & - & 2.80 & - \\
\cline { 2 - 5 } & $\mathrm{Co}^{2+}$ & - & 1.94 & \\
\hline
\end{tabular}

Коэффициенты диффузии имеют порядок $10^{-9-1} 10^{-11} \mathrm{~cm}^{2} / \mathrm{c}$, что подтверждает внутридиффузионный механизм сорбции. Коэффициент диффузии при $\mathrm{r}=0.0125 \mathrm{~cm}$ ионов меди составляет (2.99-3.68) $10^{-9} \mathrm{~cm}^{2} / \mathrm{c}$ при сорбции из бинарных растворов, коэффициент диффузии иона кобальта $-2.04 \cdot 10^{-9} \mathrm{~cm}^{2} / \mathrm{c}$, коэффициент диффузии ионов никеля в присутствии ионов меди $2.17 \cdot 10^{-9} \mathrm{~cm}^{2} / \mathrm{c}$, а в присутствии ионов кобальта $4.69 \cdot 10^{-9} \mathrm{~cm}^{2} / \mathrm{c}$. При сорбции из раствора, содержащего все три иона наибольший коэффициент диффузии у иона никеля $2.25 \cdot 10^{-9} \mathrm{~cm}^{2} / \mathrm{c}$, наименьший у иона кобальта 
$1.2 \cdot 10^{-10} \mathrm{~cm}^{2} / \mathrm{c}$. При других значениях радиуса частиц сорбента подобная тенденция сохраняется. Увеличение коэффициента диффузии при увеличении радиуса частицы (табл. 3) может быть объяснено следующим образом. При расчете $\mathrm{D}_{\mathrm{ef}}$ было сделано допущение, что частицы имеют сферическую форму, однако при увеличении радиуса частицы отклонение поверхности зерна сорбента от сферической увеличивается, это, вероятно, приводит к увеличению $\mathrm{D}_{\mathrm{ef}}$ К Кроме этого, данные приведены для природной формы цеолита, представляющего собой не однородные монокристаллы, а агрегаты в виде сростков минеральных зерен.

\section{Заключение}

На основании приведенных исследований и полученных результатов можно сделать выводы. Природная форма цеолитов Ягоднинского месторождения Камчатского края представляет собой перспективный сорбент для извлечения из водных растворов ионов меди (II), никеля (II) и кобальта (II). Кинетические модели псевдопервого и псевдо-второго порядков удовлетворительно описывают процессы сорбции ионов цветных металлов из многокомпонентных растворов цеолитами. Рассчитанные коэффициенты диффузии, константы скорости реакции $k_{l}$ (модель псевдопервого порядка, $\left.\mathrm{c}^{-1}\right)$ и $k_{2}$ (модель псевдо-второго порядка, г•ммоль-экв ${ }^{-1} \cdot \mathrm{c}^{-1}$ ), высокие значения коэффициентов корреляции подтверждают, что лимитирующей является внутридиффузионная стадия сорбции.

Сорбционная емкость цеолита из индивидуальных растворов уменьшается в ряду $\mathrm{Cu}>\mathrm{Ni}>\mathrm{Co}$ и составляет соответственно, ммоль-экв/кг: 31.7, 27.0, 23.0. На сорбцию никеля и кобальта из водных растворов сложного состава наибольшее влияние оказывает присутствие в растворе ионов меди (II), вероятно, это связано с кристаллохимическим радиусом иона меди (II), по сравнению с ионами никеля (II) и ионами кобальта (II) он наибольший.

\section{Список литературы}

1. Белова Т.П. // Сорбиионные и хроматографические проиессы. 2015. Т.15. № 5. С. 280-285.

2. Белова Т.П., Таранов С.Р., ДунинБарковский Р.Л. // Естественные и технические науки. 2014. № 9. С. 144-148

3. Белова Т.П., Гавриленко Ю.С., Ершова Л.С. // Горныцй информационноаналитический бюллетень (научнотехнический журнал). Отдельный выпуск "Камчатка". 2014. С. 300-308.

4. Шевчук В.Д. // Горный вестник Камчатки. 2008. № 3. С. $32=34$.

5. Belova T.P., Selivanova O.N. // Journal of Environmental Science and Engineering. 2012. T. 1. C. 514-522.

6. Кокотов Ю.А., Пасечник В.А. Равновесие и кинетика ионного обмена. Л. Химия. 1970. $336 \mathrm{c}$.
7. Челищев Н.Ф., Беренштейн Б.Г., Володин В.Ф. Цеолиты - новый тип минерального сырья. М. Недра. 1987. 176 с.

8. Никашина В.А. // Сорбичионые и хроматографические прочессы. 2008. Т. 8. № 2. C. 227-240.

9. Кац Э.М., Никашина В.А., Бычкова Я.В. // Сорбиионные и хроматографические проиессы. 2016. Т. 16. № 1. С. 36-43.

10.Рамазанов А.Ш., Есмаил Г.К., Свешникова Д.А. // Сорбиионные и хроматографические проиессы. 2015. Т. 15. Вып. 5. С 672682.

11.Тимофеев К.Л., Усольцев А.В., Краюхин С.А., Мальцев Г.И. // Сорбционные и хроматографические прочессы. 2015. Т. 15. Вып. 5. С 720-729.

12.Акимбаева, А.М., Ергожин Е.Е. // Журнал физической химии. 2008. Т. 82. № 3. С. 478-481. 


\section{References}

1. Belova T.P., Sorbtsionnye i khromatograficheskie protsessy, 2015, Vol. 15, No 5, pp. 280285.

2. Belova T.P., Taranov S.R., DuninBarkovskij R.L., Estestvennye $i$ tehnicheskie nauki, 2014, No 9, pp. 144-148.

3. Belova T.P., Gavrilenko Ju.S., Ershova L.S., Gornyj informacionno-analiticheskij bjulleten' (nauchno-tehnicheskij zhurnal). Otdel'nyj vypusk "Kamchatka", 2014, pp. 300-308.

4. Shevchuk V.D., Gornyj vestnik Kamchatki, 2008, No 3, pp. 32-34.

5. Belova T.P., Selivanova O.N., Journal of Environmental Science and Engineering, 2012, Vol. 1, pp. 514-522.

6. Kokotov Ju.A., Pasechnik V.A., Ravnovesie i kinetika ionnogo obmena, L., Himija, 1970, $336 \mathrm{p}$.

Белова Татьяна Павловна - к.т.н, доцент, ведущий научный сотрудник. Федеральное государственное бюджетное учреждение науки Научно-исследовательский геотехнологический центр Дальневосточного отделения Российской академии наук (НИГТЦ ДВО РАН), Петропавловск-Камчатский
7. Chelishhev N.F., Berenshtejn B.G., Volodin V.F., Ceolity novyj tip mineral'nogo syr'ja, M., Nedra, 1987, $176 \mathrm{p}$.

8. Nikashina V.A., Sorbtsionnye i khromatograficheskie protsessy, 2008, Vol. 8, No 2, pp. 227-240.

9. Kac Je.M., Nikashina V.A., Bychkova Ja.V., Sorbtsionnye $i$ khromatograficheskie protsessy, 2016, Vol. 16, No 1, pp. 36-43.

10.Ramazanov A.Sh., Esmail G.K., Sveshnikova D.A., Sorbtsionnye i khromatograficheskie protsessy, 2015, Vol. 15, No 5, pp. 672-682.

11.Timofeev K.L., Usol'cev A.V., Krajuhin S.A., Mal'cev G.I., Sorbtsionnye i khromatograficheskie protsessy, 2015, Vol. 15, No 5, pp. 720-729.

12.Akimbaeva, A.M., Ergozhin E.E., Zhurnal fizicheskoj himii, 2008, Vol. 82, No 3, pp. 478481.

Belova Tatyana P. - Ph.D (technical), associate prof. Leading Researcher, Federal State Budgetary Institution of Research Geotechnological Center, Far Eastern Branch, Russian Academy of Sciences (RGC FEB RAS), Petropavlovsk-Kamchatsky, email: tpbel@yandex.ru 